\title{
Evaluation of Quality Management Performance in the Office of the President using the Modified Public Sector Management Quality Award (PMQA) Model
}

\author{
Thoedtida Thipparat, Thongpoon Thaseepetch \\ Faculty of Engineering and Architecture, Rajamangala University of Technology, Bangkok, Thailand \\ Telephone number 882-2527029, Fax number 882-2527580, E-mail: thoedtida.t@gmail.com, \\ thaseepetch@yahoo.com
}

\begin{abstract}
This paper presents the application of an integrated VIKOR and AHP method to measure the quality management performance of departments in the Office of the President. Attributes associated with Public Sector Management Quality Award (PMQA) criteria are considered. Firstly, Analytical Hierarchy Process (AHP) is used to calculate the weights of criteria. Then, the VlseKriterijumska Optimizacija I Kompromisno Resenje (VIKOR) method is used to find the best department based on the weighted criteria achieved from the AHP. Staff in the Office of the President provided data for this study. This paper presents an application process of the integrated model for evaluating departments' performance. The results showed that the developed model could be successfully applied in the performance evaluation for departments in the Office of the President as a useful tool to assist university administrators in improving quality performance and achieving a high performance organization.
\end{abstract}

Keywords: Quality Evaluation, AHP, VIKOR

\section{Introduction}

Most educational projects are of unique and dynamic nature. Educational project have been continually criticized for not achieving the level of improvement in performance and productivity shown by other types of projects. The Office of the President has been under considerable pressure to improve the efficiency of the educational process. Pressure is also increasing from clients who demand better outputs and outcomes of shorter duration. This has created a university need for reform to challenge the change for quality management in the Office of the President. New challenges require new approaches. A vision of change for quality management within the perspective of revaluing the Office of the President is very necessary to develop a culture of continuous improvement. Global competitiveness, organizational culture and change, use of IT, performance measures and benchmarking for continuous improvement, best practices for educational management, and sustainable development are the key issues affecting educational projects.

During the 1990s, the main emphasis of Thailand's manufacturing industry was on implementing ISO 9000 standards. Although different TQM approaches and tools, such as just-in-time and total productive maintenance, have been applied since the 1980s [1], a number of foreign-owned companies within the electronics sector, and a few Thai-owned groups, have successfully implemented TQM [2]. Considering TQM positioning, Thailand ranks in the middle of the developing countries of Southeast Asia. Its status in TQM is higher than Indonesia or the Philippines, and lower than Malaysia or Taiwan [2].

For the implementation of TQM in Thailand, little empirical research has been rarely conducted in Thai manufacturing companies. The current situation of TQM implementation in Thai manufacturing companies is vague. As a result of the fact that the empirical studies in the area of TQM implementation are limited, it is difficult for Thai manufacturing companies to obtain sufficient information to support their TQM implementation process. Thus, Thai manufacturing companies are experiencing numerous difficulties, and even failures in implementing TQM. Many industries should take up the concept of total quality management (TQM) in order to improve their performance, especially for the construction industry. As Tyler and Frost [3] have pointed out, quality assurance (QA) has been taken seriously only recently in the UK construction industry, and even then only in the large contracting companies. For example, Bhattari [4] showed that none of the medium-sized 
construction companies had introduced QA systems.

One of the key emphases of a quality award is for a company to achieve sustainable financial success. In the instance of MBNQA, the award winning firms reported a $44 \%$ higher stock-price return, $48 \%$ higher growth in operating income, and a 37\% higher growth in sales than the control group of firms [5]. Organizations are using various criteria to help them during implementation efforts to evaluate themselves against criteria to determine how well their improvement efforts are progressing. Sets of criteria that the majority of organizations use include Deming prize categories, Juran's ten points, Crosby's fourteen points, and the MBNQA criteria [6]. The present study will adopt a case from Thailand as examples. Accordingly, Public Sector Management Quality Award (PMQA) criteria will be adopted as the quality management performance evaluation criteria. The PMQA has a hierarchical structure. It has seven strategic criteria. Each strategic criterion has its associated sub-criteria. Currently, several studies have been done on the development of forecasting models which have focused on engineering performance, quality performance, innovation performance and sustainability performance. However, the appropriate indicators for the Office of the President are rarely concerned. Therefore, the integration of quality management objectives and other objectives are not determined.

\section{Objective}

The research focus is to investigate the factors affecting quality management performance in the Office of the President. The main objectives include:

(1) to determine the integration of PMQA criteria;

(2) to evaluate impacts of PMQA criteria on quality management performance;

(3) to propose solutions for university administrators to improve the organizations' quality as well as to achieve high performance organization.

A newly integrated method is to enhance the process of determining or measuring a reasonable quality performance for organizations from the officers' perspective. Performance of departments in the Office of the President has been used as the data source for this study.

\section{Decision Framework}

As mentioned earlier, the objectives of this study are; first, to determine the integration of PMQA criteria. The PMQA has seven strategic criteria. Each strategic criterion has its associated sub-criteria. This study used the PMQA criteria as a guideline for developing a model. Figure 1 presents 31 sub-criteria and the integration among sub-criteria or subattributes associated with each criterion or attribute in a proposed model. In addition, the integration among attributes was considered. The second objective is to measure the impact of PMQA criteria on the quality management performance of the Office of the President. In order to realize this objective, a research framework has been developed. The framework is a simple linear model of the relationship between the independent and dependent variables. Attributes associated with PMQA criteria are considered as the independent and dependent variables for the main-model and sub-models, respectively. For the main models, the independent variables consist of six blocks including: 1) leadership (LD); 2) strategic planning (SP); 3) customers and stakeholders (CS); 4) information technology (IT); 5) human resources (HR), and; 6) process management (PM). The dependent variable is the quality management performance considered from the combination of six variables including: 1) prestige measurement; 2) unique competitive ability gaining performance; 3) customer satisfaction; 4) information management performance; 5) human resource development performance, and; 6) process management performance. In total, there are 31 sub-criteria as shown in Figure 1.

For the sub-models, the independent variables associated with each of these six blocks are determined separately. For example, the leadership model has five independent variables including: 1) operational value and ideals restructure; 2) organizational quality improving mission; 3) top managers' leading style; 4) quality culture construction, and; 5) increasing social contribution. The dependent variable is prestige measurement. Sub-attributes associated with each block are shown in Figure 2. 


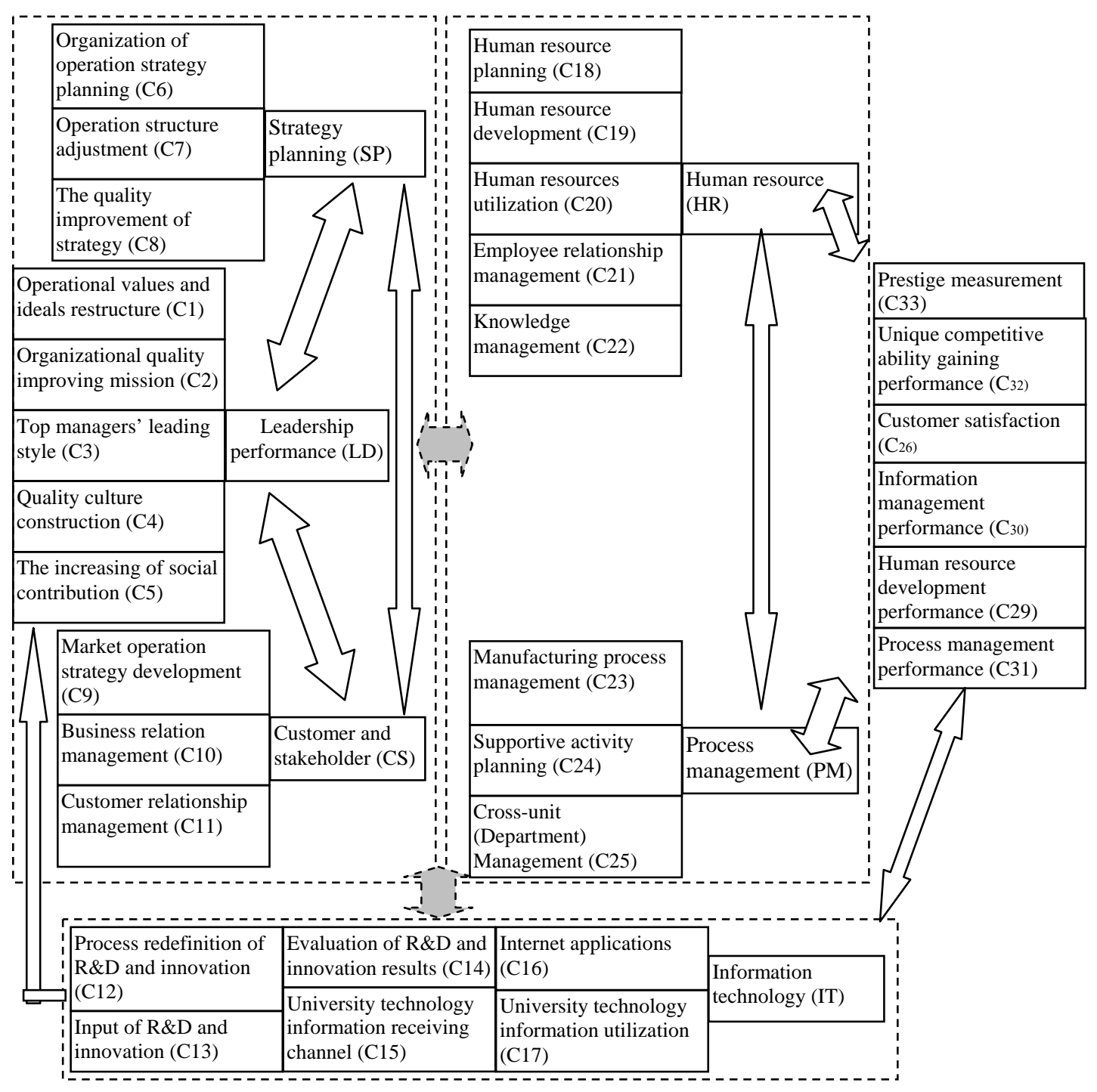

Figure 1 Criteria and Sub-Criteria of Public Sector Management Quality Award (PMQA) Model 


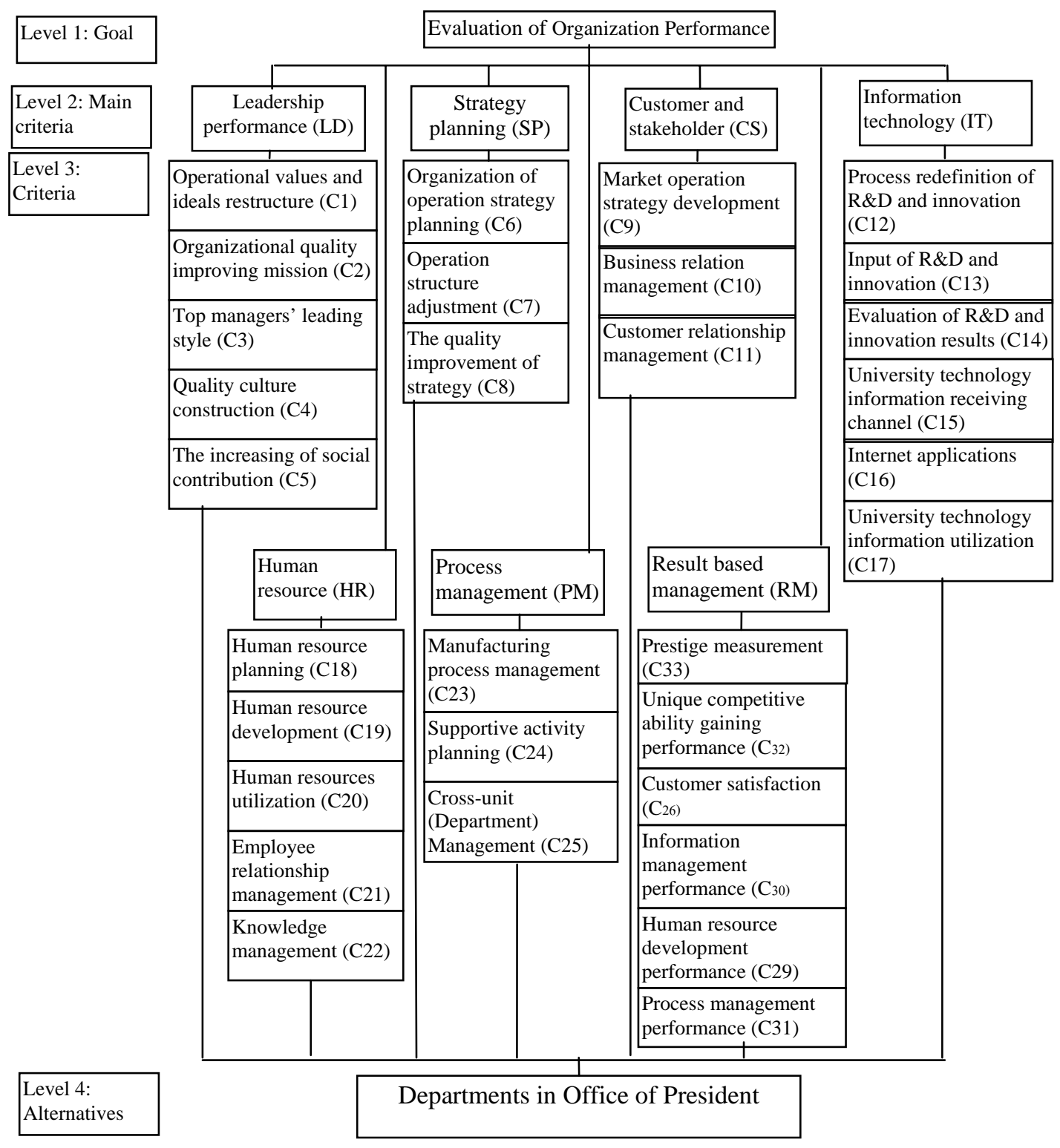

Figure 2 Hierarchical Structure of Decision Criteria

\section{Integrated VIKOR and AHP Model}

After the determination of the index system, we can employ AHP and VIKOR to carry out the evaluation of these departments. The evaluation is shown as follows:

Step 1: consider the aims of the decision making process and problem scope;

Step 2: identify decision makers who are experts in the decision making field and set decision criteria. In this study, experts include officers in each department in the Office of the President;

Step 3: acquire data associated with viewpoints of the decision makers to determine the aggregated weight of criteria, and aggregated rating of departments, and conduct a decision matrix ${ }_{L_{p} \text {-metric }} \cdot L_{p^{-}}$metric was used as an aggregating function in a compromise programming method and applied to the multicriteria measure for compromise ranking. In the proposed approach, AHP was used to compute weights of criteria, $w_{j}$ is the weight of the $j_{t h}$ criterion, expressing the relative importance of the criteria, where $j=1,2, \ldots, n$, and $n$ is the number of criteria. The departments are denoted as $A_{1}, A_{2}, \ldots, A_{i}, \ldots, A_{m}$. The rating (score) of the $j$ th criterion is denoted by $f_{i j}$ for department $A_{i}$. The form of 
$L_{p}-$ metric was introduced by Duckstein and Opricovic [7] and was formulated as follows: $L_{i}^{p}=\left\{\sum_{j=1}^{n}\left[w_{j}\left(\left|f_{j}^{*}-f_{i j}\right|\right) /\left(\left|f_{j}^{*}-f_{j}^{-}\right|\right)\right]^{p}\right\}^{\frac{1}{p}} 1 \leq p \leq \infty \quad i=1,2, \ldots, m$
Step 4 consider the best $f_{j}^{*}$, and the worst $f_{j}^{-}$values of all criterion functions, $j=1,2, \ldots, n$. In addition, an original rating matrix and a normalized weight-rating matrix of risk are applied as follows:
$\tilde{D}$

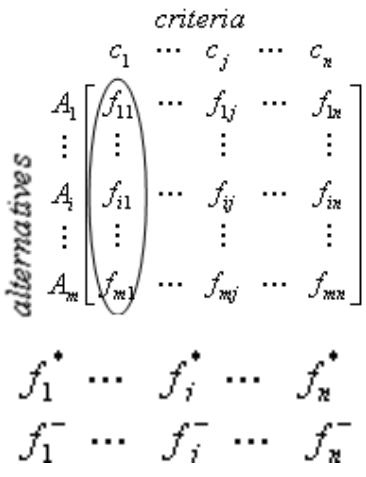

(Original data) normalized

$\Rightarrow$

$\times w_{j}$

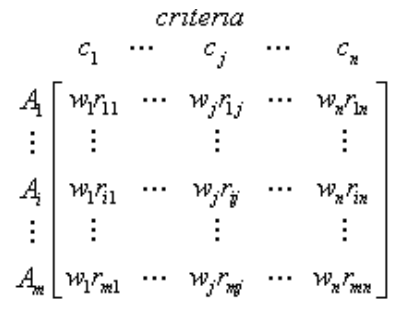

(Normalized data) where, $r_{i j}=\left(f_{j}^{*}-f_{i j} \mid\right) /\left(f_{j}^{*}-f_{j}^{-} \mid\right), f_{j}^{*}$ is the aspired/desired level and $f_{j}^{-}$is the tolerable level for each criterion.

Step 5: calculate $s_{i}$ in Eq. (2)) and $Q_{i}$ in

Eq. (3) in order to obtain the ranking measure.

$S_{i}=L_{i}^{p=1}=\sum_{j=1}^{n}\left\lfloor w_{j}\left(f_{j}^{*}-f_{i j} \mid\right)\left(\left|f_{j}^{*}-f_{j}^{-}\right|\right) \mid\right.$

$Q_{i}=L_{i}^{p=\infty}=\max _{j}\left\{w_{j}\left(\left|f_{j}^{*}-f_{i j}\right|\right) /\left(\left|f_{j}^{*}-f_{j}^{-}\right|\right) \mid j=1,2, \ldots, n\right\}$

Step 6: calculate the values $S_{i}$ and $Q_{i}$, $i=1,2, \ldots, m$, applying the relations

$S_{i}=\sum_{j=1}^{n} w_{j} r_{i j}$

$Q_{i}=\max _{j}\left\{w_{j} r_{i j} \mid j=1,2, \ldots, n\right\}$

Step 7: calculate the index values $R_{i}$,

$i=1,2, \ldots, m$, using the relation

$R_{i}=v\left(S_{i}-S^{*}\right) /\left(S^{-}-S^{*}\right)+(1-v)\left(Q_{i}-Q^{*}\right) /\left(Q^{-}-Q^{*}\right)$

Where $s^{*}=\min S_{i}$ (or setting the best $s^{*}=0$ )

$S^{-}=\max _{i} S_{i}$ (or setting the worst $S^{-}=1$ )

$Q^{*}=\min Q_{i}$ (or setting the best $Q^{*}=0$ ), $Q^{-}=\max Q_{i}$

(or setting the worst $Q^{-}=1$, and $0 \leq v \leq 1$, where $v$ is introduced as a weight.

Step 8: prioritize the departments, sorting by the value of $\left\{S_{i}, Q_{i}\right.$, and $\left.R_{i} \mid i=1,2, \ldots, m\right\}$, in decreasing order. Propose as a compromise the department $\left(A^{(1)}\right)$ which is ranked first by the measure $\min \left\{R_{i} \mid i=1,2, \ldots, m\right\}$ if the following two conditions are satisfied: Condition 1 . Acceptable advantage, $R\left(A^{(2)}\right)-R\left(A^{(1)}\right) \geq 1 /(m-1)$, where $A^{(2)}$ is the department with second position in the ranking list by $R ; m$ is the number of considered departments. Condition 2. Acceptable stability in decision making: Department $A^{(1)}$ must also be the best ranked by $\left\{S_{i}\right.$ or / and $\left.Q_{i} \mid i=1,2, \ldots, m\right\}$. The compromiseranking method is applied to obtain the compromise. Because of the fact that the solution provides maximum group utility of the majority (represented by min S, Eq. (4)), and minimum individual regret of the opponent (represented by min Q, Eq. (5)), the solution is acceptable. The weight stability intervals for the given compromise solution can be obtained from the VIKOR algorithm regarding the input weights provided by the experts [7-9].

For prioritizing departments, according to the AHP and VIKOR method, the calculated data along with the final values of $\mathrm{Ri}$ are presented. The local weights and global weights of main criteria and detailed criteria are presented in Table 1. This study ranked 5 departments including Student Affairs Department, Education Service Department, General Affairs Department, Building and Grounds Department, and Finance Department. The following calculations are considered for $L_{i}^{p}, \mathrm{Si}, \mathrm{Qi}, \mathrm{Ri} ; \mathrm{i}=1,2$, and 5 based on the process presented above. The final ranking of 5 candidates was determined based on 7 main criteria. The obtained results were verified based on two conditions in the last step so that the final ranking and compromise solution can be achieved. The acceptance advantage (Condition 1) is 
satisfied. Table 2 show results obtained from the proposed evaluation framework using 7 main criteria. It was found that the best department in Office of President was the Student Affairs Department followed by the
Education Service Department, General Affairs Department, Building and Grounds Department, and Finance Department, respectively.

\begin{tabular}{|c|c|c|c|}
\hline Main criteria & Criteria & LWt & GWt \\
\hline \multirow{5}{*}{ Leadership (LD) } & Operational values and ideals restructure (C1) & 0.543 & 0.020 \\
\hline & Organizational quality improving mission (C2) & 0.457 & 0.017 \\
\hline & Top managers’ leading style (C3) & 0.269 & 0.012 \\
\hline & quality culture construction (C4) & 0.373 & 0.017 \\
\hline & The increasing of social contribution (C5) & 0.358 & 0.016 \\
\hline \multirow{3}{*}{$\begin{array}{l}\text { Strategy planning } \\
\text { (SP) }\end{array}$} & Organization of operation strategy planning (C6) & 0.175 & 0.015 \\
\hline & Operation structure adjustment (C7) & 0.175 & 0.015 \\
\hline & The quality improvement of strategy (C8) & 0.136 & 0.011 \\
\hline \multirow{3}{*}{$\begin{array}{l}\text { Customer and } \\
\text { stakeholder (CS) }\end{array}$} & Market operation strategy development (C9) & 0.155 & 0.013 \\
\hline & Business relation management $(\mathrm{C} 10)$ & 0.165 & 0.014 \\
\hline & Customer relationship management (C11) & 0.194 & 0.016 \\
\hline \multirow{6}{*}{$\begin{array}{l}\text { Information } \\
\text { technology (IT) }\end{array}$} & Process redefinition of R\&D and innovation (C12) & 0.227 & 0.015 \\
\hline & Input of R\&D and innovation (C13) & 0.200 & 0.013 \\
\hline & Evaluation of R\&D and innovation results (C14) & 0.200 & 0.013 \\
\hline & Construction technology information receiving channel (C15) & 0.173 & 0.011 \\
\hline & Internet applications (C16) & 0.200 & 0.013 \\
\hline & Construction technology information utilization (C17) & 0.226 & 0.010 \\
\hline \multirow{5}{*}{$\begin{array}{l}\text { Human resource } \\
\text { (HR) }\end{array}$} & Human resource planning (C18) & 0.264 & 0.012 \\
\hline & Human resource development (C19) & 0.245 & 0.011 \\
\hline & Human resources utilization (C20) & 0.264 & 0.012 \\
\hline & Employee relationship management (C21) & 0.181 & 0.011 \\
\hline & Knowledge management (C22) & 0.236 & 0.015 \\
\hline \multirow{3}{*}{$\begin{array}{l}\text { Process management } \\
\text { (PM) }\end{array}$} & Manufacturing process management (C23) & 0.181 & 0.011 \\
\hline & Supportive activity planning (C24) & 0.208 & 0.013 \\
\hline & Cross-unit (Department) Management (C25) & 0.194 & 0.012 \\
\hline \multirow{6}{*}{$\begin{array}{l}\text { Result based } \\
\text { management (RM) }\end{array}$} & Customer satisfaction (C26) & 0.452 & 0.012 \\
\hline & Human resource development performance (C27) & 0.165 & 0.014 \\
\hline & Information management performance (C28) & 0.194 & 0.016 \\
\hline & Process management performance (C29) & 0.543 & 0.021 \\
\hline & Unique competitive ability gaining performance (C30) & 0.226 & 0.010 \\
\hline & Prestige measurement (C31) & 0.264 & 0.012 \\
\hline
\end{tabular}

Table 1 Local weights and global weights of main criteria and detailed criteria

\begin{tabular}{|c|c|c|c|c|c|c|c|c|c|c|c|c|c|}
\hline \multirow{2}{*}{ Criteria } & \multicolumn{5}{|c|}{ Contractor } & \multirow{2}{*}{$f * j$} & \multirow{2}{*}{$f-j$} & \multirow{2}{*}{ Wt } & \multicolumn{5}{|c|}{$w_{j}\left(f_{j}^{*}-f_{i j} \mid\right) /\left(\left|f_{j}^{*}-f_{j}^{-}\right|\right)$} \\
\hline & $\mathrm{A}$ & $\mathrm{B}$ & C & $\mathrm{D}$ & $E$ & & & & $\mathrm{~A}$ & $\mathrm{~B}$ & $\mathrm{C}$ & $\mathrm{D}$ & $E$ \\
\hline C1 & 5.000 & 5.000 & 5.000 & 4.375 & 3.125 & 5.000 & 3.125 & 0.020 & 0.000 & 0.000 & 0.000 & 0.007 & 0.020 \\
\hline $\mathrm{C} 2$ & 5.000 & 4.375 & 3.750 & 3.750 & 2.500 & 5.000 & 2.500 & 0.017 & 0.000 & 0.004 & 0.009 & 0.009 & 0.017 \\
\hline C3 & 3.750 & 3.750 & 3.125 & 1.875 & 1.250 & 3.750 & 1.250 & 0.012 & 0.000 & 0.000 & 0.003 & 0.009 & 0.012 \\
\hline $\mathrm{C} 4$ & 5.000 & 5.000 & 4.500 & 3.500 & 2.000 & 5.000 & 2.000 & 0.017 & 0.000 & 0.000 & 0.003 & 0.008 & 0.017 \\
\hline . & $\vdots$ & $\vdots$ & $\vdots$ & $\vdots$ & $\vdots$ & $\vdots$ & $\vdots$ & $\vdots$ & $\vdots$ & . & $\vdots$ & $\vdots$ & $\vdots$ \\
\hline C31 & 3.750 & 2.500 & 2.500 & 2.500 & 1.875 & 3.750 & 1.875 & 0.012 & 0.000 & 0.009 & 0.009 & 0.009 & 0.013 \\
\hline $\mathrm{Sj}$ & & & & & & & & & 0.005 & 0.096 & 0.107 & 0.215 & 0.365 \\
\hline $\mathrm{Rj}$ & & & & & & & & & 0.005 & 0.010 & 0.010 & 0.013 & 0.020 \\
\hline $\mathrm{S}$ & & & & & & & & & 0.000 & 0.127 & 0.141 & 0.292 & 0.500 \\
\hline $\mathrm{R}$ & & & & & & & & & 0.000 & 0.151 & 0.151 & 0.259 & 0.500 \\
\hline Qj & & & & & & & & & 0.000 & 0.277 & 0.292 & 0.551 & 1.000 \\
\hline Ranking & & & & & & & & & 1 & 2 & 3 & 4 & 5 \\
\hline
\end{tabular}

Note: A is Student Affairs Department, B is Education Service Department, C is General Affairs Department, D is Building and Ground Department, and E is Finance Department.

Table 2 Result obtained from VIKOR 


\section{Concluding Remarks}

A major objective of this paper was to propose an integrated VIKOR and AHP method to rank departments in the Office of the President based on their quality management performance. The decision criteria are associated with the PMQA criteria classified into seven dimensions. In the first phase, AHP is used to compute weights of criteria. In the second phase, the VIKOR method is utilized to acquire the best department based on the weighted criteria achieved from the AHP. Data was obtained from officers who were working in each department. This paper demonstrates the implementation process of the integrated methodology for performance evaluation based on PMQA criteria. The results presented that the proposed methodology could be successfully applied in the performance evaluation for benchmarking the alternative organizations as a useful tool to help university administrator and head officers in the Office of the President.

\section{References}

[1] Department of Trade and Industry, Management Best Practice-Managing into the 90s, Department of Trade and Industry, 1990.

[2] Institution of Structural Engineers, Guide to Good Management Practice for Engineering Design Offices, Institution of Structural Engineers, March 1991.

[3] Tyler, A.H. and Frost, D.T. (1993) 'Implementation of a construction industry quality assurance system', International Journal of Quality \& Reliability Management, 10(4), pp.9-18.

[4] Bhattari, D.P. (1990) Problems of quality control in construction. MSc thesis, Loughborough University of Technology, 1990.

[5] Krasachol, L., Willy, P.C.T. and Tannock, J.D.T. (1998) 'The progress of quality management in Thailand', The TQM Magazine, 10(1), pp.40-4.

[6] Tabucanon, M.T. (1993) 'Thailand's manufacturing sector: issues on development, technology, and management', Journal of Manufacturing Systems, 12(3), pp.199-203.

[7] Opricovic, S. 1998. Multi-criteria optimization of civil engineering systems. Belgrade: Faculty of Civil Engineering.
[8] Opricovic, S., \& Tzeng, G. H. 2002. 'Multicriteria planning of post-earthquake sustainable reconstruction', ComputerAided Civil and Infrastructure Engineering, 17(3), pp.211-220.

[9] Opricovic, S., \& Tzeng, G. H., 2004, 'Compromise solution by MCDM methods: A comparative analysis of VIKOR and TOPSIS', European Journal of Operational Research, 156(2), pp.445-455. 